\title{
Invasive group A streptococcal infection outbreaks of type emm118 in a long-term care facility, and of type emm74 in the homeless population, Montréal, Quebec
}

\author{
PA Pilon ${ }^{1,2}$,, N Savard ${ }^{1,3}, \mathrm{~J}$ Aho ${ }^{1,4}$, J Caron ${ }^{1}$, A Urbanek${ }^{1}$, R Paré ${ }^{1}$, P Le Guerrier ${ }^{1,2}$, C Savard ${ }^{1}$, \\ K Hammond-Collins ${ }^{4}$, C Dung Tran ${ }^{1}$, R Allard ${ }^{1,3}$, MC Domingo ${ }^{5}$
}

\begin{abstract}
Background: Two invasive group A streptococcus (iGAS) infection outbreaks occurred in Montréal in 2016 and 2017; one in a long-term care facility (type emm118) and one in the community, primarily involving homeless people (type emm74).
\end{abstract}

Objective: To describe two recent iGAS outbreaks in Montréal and highlight the challenges in dealing with these outbreaks and the need to tailor the public health response to control them.

Methodology: All cases of iGAS were investigated and the isolates were sent to the laboratory for emm typing. In both outbreaks, cases of superficial group A streptococcus (GAS) infection were identified, through 1) systematic case detection accompanied by screening for asymptomatic carriers among residents and employees of the long-term care facility and 2) sentinel surveillance among homeless people. Visits were made to community organizations providing homeless services (including shelters) and social networks were analyzed to establish whether there were any links among cases of GAS infection (both invasive and noninvasive) and locations frequented. In both outbreaks, recommendations were made to service providers regarding enhancement of infection prevention and control measures.

Results: In the long-term care facility, five cases of type emm118 iGAS were identified over a 22-month period, one of which resulted in death. All residents were screened and no carriers were identified. Among the employees, 81 (65\%) were screened and four carriers were identified. Of those, one was a carrier of type emm118 GAS. All carriers were treated, and subsequent follow-up sampling on three carriers (including the one with emm118) was negative.

In the community, 23 cases of type emm74 iGAS were detected over a 16-month period, four of which resulted in death. Half of the cases $(n=12)$ were described as homeless, and six others were users of services for the homeless. Sentinel surveillance of superficial infections yielded 64 cultures with GAS, chiefly on the skin, including 51 (80\%) of type emm74. An analysis of the social networks revealed the large number and variety of resources for the homeless used by the cases. Visits to the community organizations providing homeless services revealed the heterogeneity and precariousness of some of these services, the difficulties encountered in applying adequate health and hygiene measures, and the high degree of mobility amongst those who use these services.
This work is licensed under a Creative Commons Attribution 4.0 Internationa License.



Affiliations

${ }^{1}$ Secteur Prévention et contrôle des maladies infectieuses, Direction régionale de santé publique, Centre intégré universitaire de santé et de services sociaux du Centre-Sud-de-l'Île-de-Montréal [Infectious Disease Prevention and Control Division, Regional Public Health Directorate, Integrated Health and Social Services University Network for South-Central Montréal], Montréal, QC

${ }^{2}$ École de santé publique [School of Public Health], Université de Montréal, Montréal, QC

${ }^{3}$ Department of Epidemiology, Biostatistics and Occupational Health, McGill University, Montréal, QC

${ }^{4}$ Public Health Agency of Canada, Ottawa, ON

${ }^{5}$ Laboratoire de santé publique du Québec [Quebec Public Health Laboratory], Sainte-Anne-de-Bellevue, QC

*Correspondence: pierre.a.pilon. ccsmt|@ssss.gouv.qc.ca 
Conclusion: The detection and control of iGAS outbreaks in both long-term care establishments and among community organizations providing homeless services are very complex. An outbreak of iGAS can develop in the background over a long time and be easily overlooked despite cases being admitted to the hospital. Emm typing and systematic research of previous cases of iGAS are essential tools for the detection and characterization of outbreaks. Close cooperation among public health agencies, clinical teams, community organizations and laboratories is essential for proper monitoring and the reduction of GAS transmission in the community and health care settings.

Suggested citation: Pilon PA, Savard N, Aho J, Caron J, Urbanek A, Paré R, Le Guerrier P, Savard C, Hammond-Collins K, Dung Tran C, Allard R, Domingo MC. Invasive group A streptococcal infection outbreaks of type emm118 in a long-term care facility, and of type emm74 in the homeless population, Montréal, Quebec. Can Commun Dis Rep 2019;45(1):24-31. https://doi.org/10.14745/ccdr.v45i01a03

Keywords: invasive, infection, group A streptococcus, long-term care facility, homeless population

\section{Introduction}

The $\beta$-hemolytic group A streptococcus (GAS) (Streptococcus pyogenes) is a bacterium that is transmitted primarily through droplet inhalation or via skin contact. Sites such as the oropharynx and skin can be asymptomatically colonized. There is a spectrum of infections that can be caused by GAS, ranging from benign infections, such as pharyngitis or impetigo, to invasive infections, such as bacteremia, necrotizing fasciitis or streptococcal toxic shock syndrome (1). The sequencing of a portion of the emm gene, which codes for a virulence factor called the M protein, allows the identification of 220 distinct strains, called emm types (2).

The risk factors for invasive GAS (iGAS) infections include advanced age, skin lesions or breaks, viral respiratory infections, some chronic diseases such as diabetes, immunosuppression, use of intravenous drugs and excessive use of alcohol (1,3-5).

In Quebec, iGAS is a notifiable disease. The Direction régionale de santé publique (DRSP) [Regional Public Health Department], Centre intégré universitaire de santé et de services sociaux (CIUSSS) du Centre-Sud-de-l'Île-de-Montréal handles such reports for a population base of approximately two million people. Cases of iGAS reported by labs and physicians are systematically investigated by the DRSP to identify the severity of the infection, the associated risk factors and any close contacts who might benefit from prophylaxis as per provincial recommendations (6). Since 2010, isolated strains from sterile sites have been sent to the Laboratoire de santé publique du Québec (LSPQ) [Quebec Public Health Laboratory], then to the National Microbiology Laboratory (NML), which does the emm gene typing. An antibiogram is performed to test for sensitivity to penicillin, ceftriaxone, erythromycin, clindamycin and vancomycin. Surveillance statistics show that the incidence of iGAS is on the rise in Montréal, the province of Quebec as a whole and across Canada (Figure 1) (6-9).
Figure 1: Incidence of invasive group A streptococcal infections for Montréal, the province of Quebec and Canada, 2000-2017

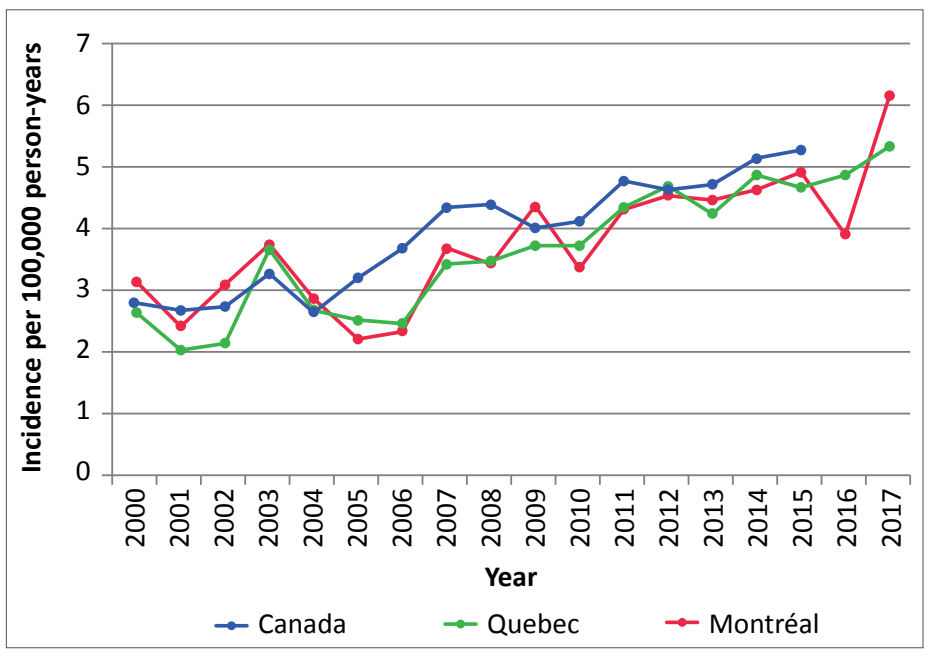

Sources: Public Health Agency of Canada. Number of invasive cases of group A streptococcal infections reported between 1994 and 2015 - Notifiable diseases online (consulted February 21, 2018); Institut national de santé publique du Québec. Rapport hebdomadaire/annuel des maladies à déclaration obligatoire d'origine infectieuse [Weekly/Annual Report of Infectious Notifiable Diseases] (consulted February 21, 2018)

In 2016 and 2017, the DRSP detected two outbreaks of iGAS in very different populations: in residents of a long-term care facility; and in a homeless population. The goal of this article is to describe these two outbreaks and to illustrate the challenges encountered and the need to tailor responses to the specific affected populations.

\section{Outbreak in a long-term care facility}

\section{Background}

Due to a combination of host- and environment-related factors, elderly people in a long-term care environment are at higher risk of contracting and dying from iGAS $(10,11)$. Several iGAS outbreaks, occurring mostly over periods of a few months, 
have been reported in this type of setting within Canada and elsewhere in the world $(3,12-15)$.

In Quebec, the recommendation is to conduct a 30-day surveillance after any iGAS case is reported in a long-term care resident. If the iGAS case is severe (meningitis, pneumonia, soft-tissue necrosis, toxic shock or death), antibiotic prophylaxis is given to all close contacts and a retrospective investigation is conducted for the previous 30 days (6). If a high number of cases are identified, the recommendation is to look for asymptomatic carriers and carry out a prospective surveillance of invasive and noninvasive GAS infections $(6,7)$.

\section{Methodology \\ Detection of the outbreak}

In July and August 2016, two cases of type emm118 iGAS were reported to the DRSP by a long-term care facility that accommodated approximately 200 residents. The public health investigator noted that other cases of iGAS had occurred in the same long-term care facility over the two previous years. The period covered by the investigation was therefore expanded beyond the routinely recommended 30-day retrospective period.

\section{Definition of a case}

A confirmed case of iGAS is defined as being a long-term care facility employee or resident in whom type emm118 GAS was isolated from a normally sterile site any time after January 1, 2014. Asymptomatic carriers or superficial GAS infections are defined as being an employee or resident in whom type emm118 GAS was isolated from a non-sterile site (oropharynx, wound) any time after January 1, 2014.

\section{Search for cases}

All cases of iGAS reported to the DRSP by this long-term care facility were reviewed. Lab results positive for GAS (as of January 1, 2014) for residents of the long-term care facility and patients of its referring hospital were retrospectively reviewed to identify cases of iGAS that may not have been reported as well as cases of noninvasive GAS infection. Active surveillance began in August 2016 and continued until April 2017 to detect type emm118 GAS, whether invasive or not.

Screening for asymptomatic carriers was proposed to all residents and health care staff via throat swabs and, if applicable, wound swabs. This screening offer started in the summer of 2016 and continued for 12 weeks.

\section{Microbiological analyses}

The NML performed emm typing of isolates from both sterile and non-sterile sites. While awaiting the results of emm typing, the LSPQ conducted pulsed-field gel electrophoresis (PFGE) on isolates taken from iGAS cases to confirm similarities between invasive strains.

\section{Data analysis}

The descriptive analyses and the epidemic curve were derived using Microsoft ${ }^{\mathrm{TM}}$ Excel 2010 software.

\section{Results}

Five confirmed cases of type emm118 iGAS were identified via the systematic review of cases reported to the DRSP. Pulsed-field gel electrophoresis analyses indicated the same profile for these strains. All type emm118 isolates were sensitive to all antibiotics tested. A review of patient records in the facility and prospective surveillance revealed no additional cases.

All cases of type emm118 iGAS were found in men 71 to 84 years of age. All had comorbidities, notably kidney failure, chronic obstructive pulmonary disease, immunosuppression or cirrhosis. None had any chronic wounds, skin infections or skin diseases. Four cases presented a serious infection (one death from streptococcal toxic shock and three cases of pneumonia) and one case presented with bacteremia. All of the cases occurred between November 2014 and August 2016 (Figure 2). No close contacts between cases of type emm118 iGAS were identified.

Figure 2: Epidemic curve of cases of invasive type emm118 group A streptococcal infection in a Montréal long-term care facility, 2014-2016 $(n=5)$

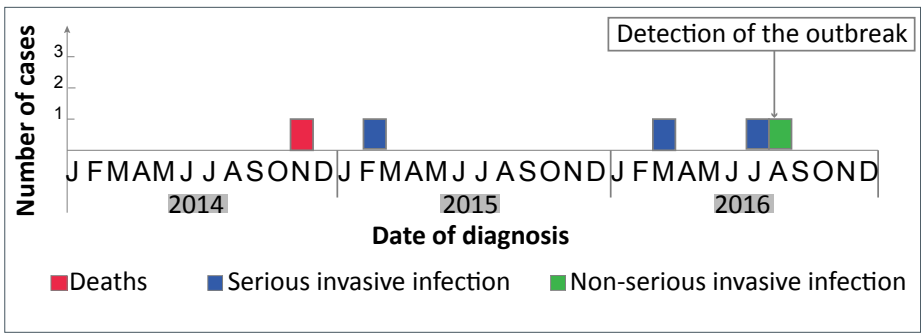

All residents were screened. None of them were GAS carrier. Among employees, 81/125 (65\%) were tested: four were GAS carriers, one of whom was emm118-positive. This particular person was working in the facility when the five cases of iGAS were reported. All employees who were carriers were withdrawn from work for the first 48 hours of treatment (10 days of oral penicillin $\mathrm{V}$, amoxicillin or cefadroxil). The success of the treatment was ascertained by an oropharyngeal culture from three of the four employees, including the carrier of the emm118 strain (6). No further cases were identified in the subsequent six months.

\section{Outbreak in a homeless population}

\section{Background}

Due to a combination of risk factors, homeless individuals are at greater risk of iGAS $(16,17)$. They are over-represented among reported cases in Montréal (unpublished data), although no outbreak had been previously documented among this 
population in Montréal. Elsewhere, outbreaks of iGAS have been reported among intravenous drug users (18-23) and, more recently, among homeless populations (24-28).

\section{Methodology}

\section{Detection of the outbreak}

Between March and May 2017, the DRSP received reports of two cases of iGAS at the same shelter. These two instances led to a review of all cases reported among homeless people in 2017. A greater number of cases $(n=7)$ had occurred in this population since January 2017, compared with the same period in the preceding year $(n=3)$. The first five cases for which the emm type was identified were of emm74 type. This emm type had not previously been reported in Montréal.

\section{Definition of cases}

An iGAS outbreak case was defined as a person living in Montréal, with isolation of type emm74 GAS from a normally sterile site between March 1, 2017 and July 31, 2018. An outbreak case with superficial (noninvasive) infection was defined as being a person identified by the sentinel surveillance initiated during the outbreak and having at least one culture from a non-sterile site testing positive for type emm74 GAS.

\section{Investigation of cases}

Following detection of the outbreak, the iGAS cases were again investigated to identify which homeless services and shelters were used during the month preceding the appearance of symptoms or, if accurate timing was impossible, the generally frequented places. For new cases, several investigations were conducted in person with the cases, in order to obtain more comprehensive information about their risk factors, places frequented and close contacts.

\section{Surveillance of noninvasive infections}

A sentinel surveillance of cases of superficial infection was initiated in July 2017. The main clinical teams working with the homeless population were asked to look for any wounds that seemed infected, to swab these wounds for culture and to fill out a short survey documenting the homeless services and shelters used in the two preceding weeks. The cultured GAS strains were sent to the LSPQ, then to the NML for emm typing.

\section{Data analysis}

Descriptive statistics and the comparison with sporadic cases of iGAS in Montréal were performed with IBM Cognos Business Intelligence ${ }^{\mathrm{TM}}$ 10.2.2 software (International Business Machines Corp., Armonk, New York, US), Microsoft Excel 2010 and Stata ${ }^{\text {TM }}$ 15 (StataCorp, College Station, Texas, US). Social networks were analyzed using the Pajek 5.04 application. The resulting network includes cases of iGAS, their close contacts as defined in Quebec guidelines (6), the cases of superficial GAS infection detected via sentinel surveillance and the places frequented (i.e., shelters and other residential locations, day centres, clinical services for the homeless and gathering places).

\section{Intervention}

The DRSP worked in close cooperation with the Service régional en itinérance [Regional Homeless Service], clinical teams working with the homeless, and several dozen community agencies that operate shelters, day centres and other services for the homeless.

In June, an alert was sent out to the health care network and recommendations for basic hygiene measures were forwarded to community organizations providing services to the homeless. Recommendations focused on the early detection of infected wounds, swabbing them for culture and on their treatment. In July the sentinel surveillance system for monitoring wounds was established.

Throughout June and July, the DRSP visited nine shelters and three day centres to assess the situation and issue more specific recommendations to decrease the transmission of infections, to facilitate hygiene and cleanliness, and to control infestations by ectoparasites, as these could lead to wounds initiated from scratching. In October, follow-up visits were conducted to evaluate the implementation of recommendations and to distribute a reader-friendly information poster to inform people using these homeless services of the ways they can protect themselves. As recommended by provincial guidelines (6), antibiotic prophylaxis for people who had close contact with severe cases of iGAS was offered whenever possible.

\section{Results}

The first iGAS case of this outbreak occurred in March 2017. The outbreak was declared over on July 31, 2018, after eight consecutive months with no excessive cases of iGAS among homeless services users. The outbreak had 23 cases of iGAS, 19 of which were reported between March and November 2017. The cases of iGAS included 14 men and nine women from 34 to 80 years of age (median=54).

The most common clinical presentations were soft-tissue infections ( $n=14$, including five cases of necrotizing fasciitis) and bacteremia $(n=7)$. All were hospitalized, eight went into toxic shock and four died. Half of the cases $(n=12)$ were homeless when the infection occurred, six were not homeless but had used homeless services, and three had an epidemiological link to this population. Two subjects had no links to this population. Twelve people consumed excess alcohol and three used intravenous drugs.

The outbreak's iGAS cases were significantly different from the sporadic cases reported in Montréal during the same period (Table 1). All of the emm74 iGAS isolates were sensitive to all of the antibiotics tested. 
Table 1: Comparison of cases from the invasive type emm74 group A streptococcal infections with other cases from the same period

\begin{tabular}{|c|c|c|c|c|c|}
\hline \multirow[t]{2}{*}{ Characteristics } & \multicolumn{2}{|c|}{$\begin{array}{l}\text { Type emm74 } \\
\text { March } 2017 \\
\text { to July } 2018\end{array}$} & \multicolumn{2}{|c|}{$\begin{array}{l}\text { Other emm type } \\
\text { or unknown } \\
\text { March } 2017 \text { to } \\
\text { July } 2018\end{array}$} & \multirow[t]{2}{*}{$P$ value ${ }^{a}$} \\
\hline & $N=23$ & $\%$ & $N=167$ & $\%$ & \\
\hline $\begin{array}{l}\text { Median age } \\
\text { (years) }\end{array}$ & 54 & N/A & 46 & N/A & N/A \\
\hline Male & 14 & 60.9 & 93 & 55.7 & 0.662 \\
\hline Hospitalized & 23 & 100.0 & 153 & 91.6 & 0.225 \\
\hline Death & 4 & 17.4 & 10 & 6.0 & 0.072 \\
\hline \multicolumn{6}{|l|}{ Infection types } \\
\hline Soft tissue ${ }^{b}$ & 14 & 60.9 & 64 & 38.3 & $0.045^{d}$ \\
\hline Respiratory $^{c}$ & 3 & 13.0 & 28 & 16.8 & 1.000 \\
\hline Bacteremia & 7 & 30.4 & 35 & 21.0 & 0.295 \\
\hline Toxic shock & 8 & 34.8 & 19 & 11.4 & $0.007^{d}$ \\
\hline \multicolumn{6}{|l|}{ Risk factors } \\
\hline Homelessness & 12 & 52.2 & 8 & 4.8 & $<0.001^{d}$ \\
\hline Drugs & $4^{e}$ & 17.4 & 11 & 6.6 & 0.090 \\
\hline Alcoholism & 12 & 52.2 & 17 & 10.2 & $<0.001^{d}$ \\
\hline Diabetes & 5 & 21.7 & 20 & 12.0 & 0.195 \\
\hline $\begin{array}{l}\text { Chronic } \\
\text { pulmonary } \\
\text { diseases }\end{array}$ & 6 & 26.1 & 11 & 6.6 & $0.008^{d}$ \\
\hline
\end{tabular}

Abbreviations: N/A, not applicable; $N$, total number; $<$, inferior to

a Fisher's exact test for comparison of cases of invasive group A streptococcal infections type emm74 and those of other or unknown emm type

${ }^{b}$ Soft tissue infections include soft tissue necrosis, fasciitis, myositis and/or cellulitis or erysipelas

' Respiratory infections include pneumonia or other pulmonary manifestation and/or pharyngitis/

tonsillitis

d Statistically significant $(\alpha=0.05)$

e Including intravenous and oral drugs

Figure 3: Analysis of social networks for cases of invasive and noninvasive emm74 a type group A streptococcal infections
Of a total of 156 specimens submitted, sentinel surveillance detected 63 wounds and one throat that had been infected or colonized by GAS, of which 51 (80\%) were type emm74. An analysis of the social networks revealed eight components, the chief of which linked $68 \%$ of iGAS cases and $81 \%$ of superficial infection cases (Figure 3). Some locations had been frequented by a greater number of cases (four cases of iGAS for one location, 17 noninvasive cases for another), but no single environment was directly linked with a majority of cases.

For the nine severe cases of iGAS who used homeless services or were epidemiologically related, only four close contacts could be identified for antibiotic prophylaxis. The community organizations had been alerted to the importance of prevention measures, but the necessary resources were not always available, which introduced some variability with respect to the application of prevention and treatment measures. The main challenges encountered were the frequency of housekeeping, the cleaning of beds and bed linens, the laundering of clothing and the availability of a change of clothing. Noteworthy improvements were observed in some organizations during follow-up visits.

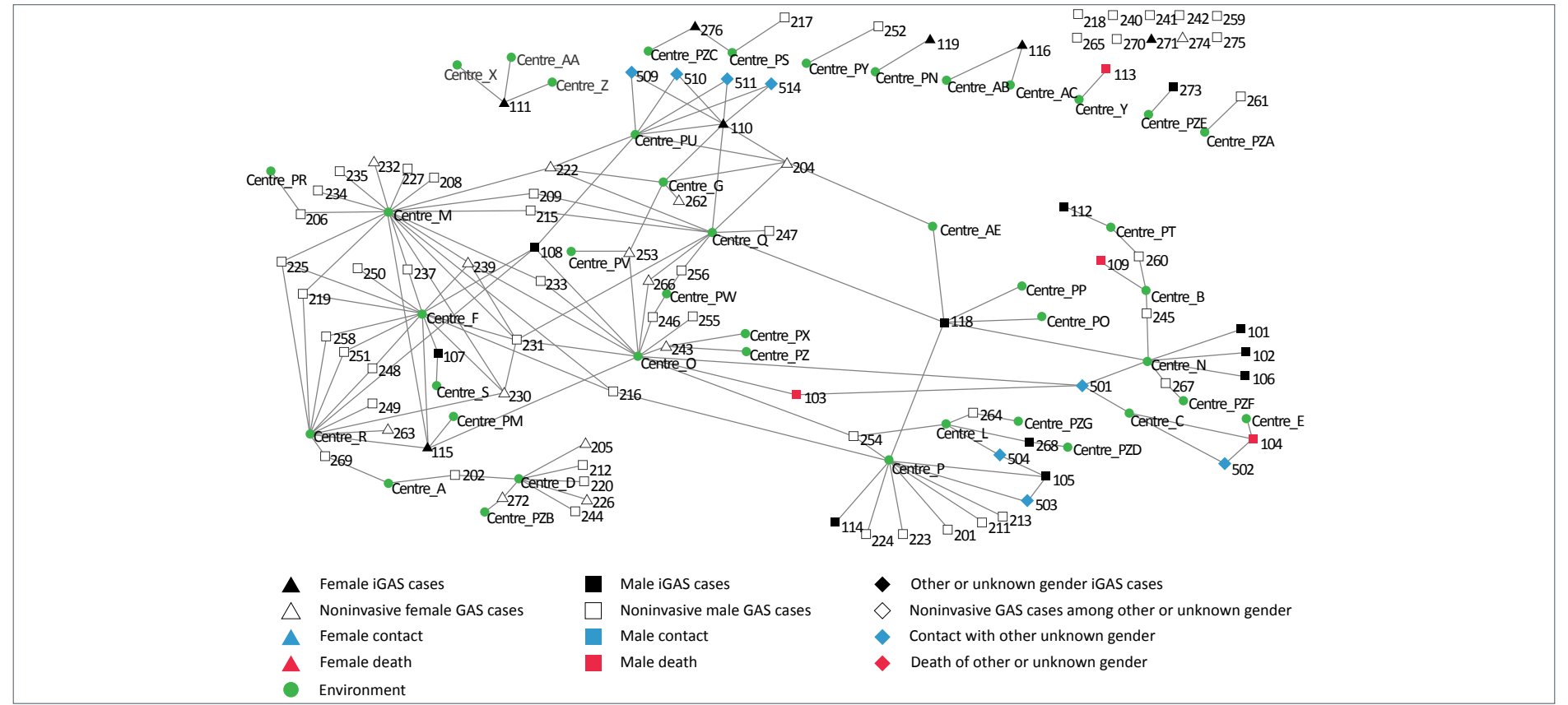

Abbreviations: GAS, group A streptococcus; iGAS, invasive group A streptococcus

a The network illustrated excludes two cases of iGAS from the outbreak that were epidemiologically unrelated to the homeless population. It includes one case of type emm74 iGAS in a nonMontrealer who was epidemiologically related to the homeless population 


\section{Discussion}

Managing these two iGAS outbreaks in two very different contexts identified both common and context-specific challenges. Detecting the outbreak proved to be a challenge in both contexts. For the long-term care outbreak, the length of time between cases led to a 21-month delay between the appearance of the first case and the detection of the outbreak. For the outbreak among the homeless population, detection was more timely but could have been delayed had two related cases not been reported in the same shelter. The absence of specific surveillance by emm type was a limiting factor in the detection of both outbreaks.

The long-term care outbreak was characterized by its long-lasting nature and the presence of the same emm type in an employee. In the absence of close contact among the different cases of iGAS, the most likely assumption is transmission via an asymptomatic carrier, possibly the emm118 GAS-positive employee, although this person could also have been a secondary case, with the primary case being an unidentified carrier. The work of long-term care personnel in identifying and dealing with similar future outbreaks could be facilitated with the development of an operational protocol for screening, treatment and follow-up of screened employees. The DRSP's recommendation to long-term care facility was to continue prospective surveillance of GAS infections for a minimum of six months after the last identified case, even though the optimal timing for prospective surveillance is currently unknown (29). Of note, no further cases of iGAS infection were detected at the long-term care facility during this additional surveillance period. Enhancement of infection prevention and control measures, and detection and treatment of the emm118 GAS carrier, may have contributed to this outcome, as it has been reported in other outbreaks $(5,12,29,30)$.

For the homeless population outbreak, analysis of the social network and sentinel surveillance revealed that the outbreak was not limited to one specific setting. Rather, the strain involved was found to be circulating throughout the homeless population. This population is inherently mobile: homeless people can sleep in different places and call upon different resources, which would account for widespread transmission. This mobility creates a daunting challenge in terms of intervention. Other challenges encountered included limited human and financial resources available for the application of recommendations regarding hygiene and cleanliness, mental health issues among the users, which make it difficult to apply personal hygiene measures and treat infestations, the difficulty of accessing proper care and the wide variety of community organizations involved. In addition, there is no way of assessing the effectiveness of the public health interventions and distinguishing their effect from the natural evolution of the outbreak.

These iGAS outbreaks have identified the need for improved detection methods. Emm typing of iGAS and systematic search for previous cases of iGAS are essential tools for detecting and characterizing outbreaks. These outbreaks have also prompted the development of more effective ways of collaboration between clinical partners, community organizations and laboratories to pave the way for setting-specific interventions. The development of intervention strategies to identify and control iGAS outbreaks in vulnerable populations, whether in the community or in a health care setting, is especially relevant in a context where the incidence of iGAS is on the rise in Canada.

\section{Authors' statement}

All the authors - PAP, NS, JA, JC, AU, RP, PLG, CS, KHC, CDT, $\mathrm{RA}$, and $\mathrm{MCD}$ - have contributed to managing different aspects of either or both of the outbreaks.

The authors - JA, PAP and RP — wrote the first versions of the manuscript on the long-term care facility outbreak and the others authors - CDT, RA and MCD - have contributed to the final version by providing precisions, feedback and suggestions.

The authors - NS and PAP — wrote the first versions of the manuscript on the outbreak in the homeless population and the other authors - JC, AU, PLG, CS, KHC and MCD - have contributed to the final version by providing precisions, feedback and suggestions.

\section{Conflict of interest}

None.

\section{Acknowledgements}

We thank the investigators who investigated the cases, in particular Mr. Guy Lapierre, nurse, for his vigilance and his excellent work as well as the staff of the Direction régionale de santé publique for data collection. We thank Ms. Johanne Sicotte and Mrs. Annie Parisien from the infection prevention and control team and Ms. Manon Aubé in occupational health at the establishment to which the long-term care facility was attached for their indispensable collaboration.

We thank the Service régional en itinérance et activités communautaires of the Centre intégré universitaire de santé et de services sociaux (CIUSSS) du Centre-Sud-de-I'Île-de-Montréal; the clinical staff of the shelters, the clinical care team of the CIUSSS du Centre-Sud-de-l'île-de-Montréal and of the CIUSSS-du-Centre-Ouest-de-l'île-de-Montréal, the hospital laboratories (Centre Hospitalier Universitaire de Montréal, McGill University Health Centre) and Doctors of the World who participated in sentinel surveillance; and staff and services who work with the homeless population and who have worked closely on the implementation of public health recommendations.

We also thank the following people who contributed to the work at some point: Dr. Carole Morissette, Ms. Maryse Lapierre, Dr. Marie Munoz-Bertrand, Dr. Marie-Jo Ouimet, Ms. Manon 
Dugas, Ms. Karyne Daigle, Ms. Deboray Bonney, Ms. Mélanie Tailhandier, Mrs. Mireille Carpentier, Mr. Chérif Trabelsi, Dr. David Kaiser, Mrs. Isabelle Rouleau and Dr. Richard Massé.

Finally, we thank Ms. Cindy Lalancette of the Laboratoire de santé publique du Québec for the analysis of pulsed-field gel electrophoresis profiles; Dr. Irene Martin and staff of the National Microbiology Laboratory for their collaboration in laboratory analysis.

\section{References}

1. Efstratiou A, Lamagni T. Epidemiology of Streptococcus pyogenes. 2016 Feb 10 [Updated 2017 Apr 3]. In: Ferretti JJ, Stevens DL, Fischetti VA, editors. Streptococcus pyogenes: Basic Biology to Clinical Manifestations. Oklahoma City (OK): University of Oklahoma Health Sciences Center; 2016. PubMed

2. Sanderson-Smith M, De Oliveira DM, Guglielmini J, McMillan DJ, Vu T, Holien JK, Henningham A, Steer AC, Bessen DE, Dale JB, Curtis N, Beall BW, Walker MJ, Parker MW, Carapetis JR, Van Melderen L, Sriprakash KS, Smeesters PR; M Protein Study Group. A systematic and functional classification of Streptococcus pyogenes that serves as a new tool for molecular typing and vaccine development. J Infect Dis 2014 Oct;210(8):1325-38. DOI PubMed

3. Jordan HT, Richards CL Jr, Burton DC, Thigpen MC, Van Beneden CA. Group a streptococcal disease in long-term care facilities: descriptive epidemiology and potential control measures. Clin Infect Dis 2007 Sep;45(6):742-52. DOI PubMed

4. Rainbow J, Jewell B, Danila RN, Boxrud D, Beall B, Van Beneden C, Lynfield R. Invasive group a streptococcal disease in nursing homes, Minnesota, 1995-2006. Emerg Infect Dis 2008 May;14(5):772-7. DOI PubMed

5. Dooling KL, Crist MB, Nguyen DB, Bass J, Lorentzson L, Toews KA, Pondo T, Stone ND, Beall B, Van Beneden C. Investigation of a prolonged Group A Streptococcal outbreak among residents of a skilled nursing facility, Georgia, 2009-2012. Clin Infect Dis 2013 Dec;57(11):1562-7. DOl PubMed

6. Ministère de la Santé et des Services sociaux. Guide d'intervention - Les infections invasives à streptocoque du groupe A. Gouvernement du Québec, 2007 (last modification 2016), 80 p. http://publications.msss.gouv. qc.ca/msss/document-000502/

7. Public Health Agency of Canada. Guidelines for the Prevention and Control of Invasive Group A Streptococcal Disease. Can Commun Dis Rep 2006; 32S2. 1-26. https:// www.canada.ca/content/dam/phac-aspc/migration/phacaspc/publicat/ccdr-rmtc/06pdf/32s2_e.pdf

8. Public Health Agency of Canada. National Laboratory Surveillance of Invasive Streptococcal Disease in Canada - Annual Summary 2015. Ottawa (ON): PHAC; 2015. https://www.canada.ca/en/public-health/services/ publications/drugs-health-products/national-laboratory- surveillance-invasive-streptococcal-disease-canada-annualsummary-2015.html

9. Ministère de la Santé et des Services sociaux. Surveillance épidémiologique rehaussée des infections invasives à streptocoque du groupe A dans la province de QuébecBilan du 18 janvier 2009 au 17 janvier 2011. Québec (QC): SSSQ; 2014. 73 p. http://publications.msss.gouv.qc.ca/msss/ document-000511/

10. Saavedra-Campos $M$, Simone B, Balasegaram $S$, Wright $A$ Usdin $M$, Lamagni T. Estimating the risk of invasive group $A$ Streptococcus infection in care home residents in England, 2009-2010. Epidemiol Infect 2017 Oct;145(13):2759-65. DOI PubMed

11. Thigpen $M C$, Richards $C L$ Jr, Lynfield $R$, Barrett $N L$, Harrison LH, Arnold KE, Reingold A, Bennett NM, Craig AS, Gershman K, Cieslak PR, Lewis P, Greene CM, Beall B, Van Beneden CA; Active Bacterial Core surveillance / Emerging Infections Program Network. Invasive group A streptococcal infection in older adults in long-term care facilities and the community, United States, 1998-2003. Emerg Infect Dis 2007 Dec;13(12):1852-9. DOI PubMed

12. Greene CM, Van Beneden CA, Javadi M, Skoff TH, Beall B, Facklam R, Abercrombie DR, Kramer SL, Arnold KE. Cluster of deaths from group $A$ streptococcus in a long-term care facility--Georgia, 2001. Am J Infect Control 2005 Mar;33(2):108-13. DOI PubMed

13. Smith A, Li A, Tolomeo O, Tyrrell GJ, Jamieson F, Fisman D. Mass antibiotic treatment for group A streptococcus outbreaks in two long-term care facilities. Emerg Infect Dis 2003 Oct;9(10):1260-5. DOI PubMed

14. Thigpen MC, Thomas DM, Gloss D, Park SY, Khan AJ, Fogelman VL, Beall B, Van Beneden CA, Todd RL, Greene CM. Nursing home outbreak of invasive group a streptococcal infections caused by 2 distinct strains. Infect Control Hosp Epidemiol 2007 Jan;28(1):68-74. DOI PubMed

15. Cummins A, Millership S, Lamagni T, Foster K. Control measures for invasive group A streptococci (iGAS) outbreaks in care homes. J Infect 2012 Feb;64(2):156-61. DOI PubMed

16. Tyrrell GJ, Lovgren M, St Jean T, Hoang L, Patrick DM, Horsman G, Van Caeseele P, Sieswerda LE, McGeer A, Laurence RA, Bourgault AM, Low DE. Epidemic of group A Streptococcus M/emm59 causing invasive disease in Canada. Clin Infect Dis 2010 Dec;51(11):1290-7. DOI PubMed

17. Athey TB, Teatero S, Sieswerda LE, Gubbay JB, Marchand-Austin A, Li A, Li A, Wasserscheid J, Dewar K, McGeer A, Williams D, Fittipaldi N. High incidence of invasive group A Streptococcus disease caused by strains of uncommon emm types in Thunder Bay, Ontario, Canada. J Clin Microbiol 2016 Jan;54(1):83-92. DOl PubMed

18. Efstratiou A, Emery M, Lamagni TL, Tanna A, Warner M, George RC. Increasing incidence of group A streptococcal infections amongst injecting drug users in England and Wales. J Med Microbiol 2003 Jun;52(6):525-6. DOI PubMed

19. Irish C, Maxwell R, Dancox M, Brown P, Trotter C, Verne J, Shaw M. Skin and soft tissue infections and vascular 
disease among drug users, England. Emerg Infect Dis 2007 Oct;13(10):1510-1. DOI PubMed

20. Sierra JM, Sánchez F, Castro P, Salvadó M, de la Red G, Libois A, Almela M, March F, Español M, Sambeat MA, Romeu J, Brugal MT, García de Olalla P, Gatell JM, Vila J, García F, López Colomés JL, Caylà JA, Coll P. Group A streptococcal infections in injection drug users in Barcelona, Spain: epidemiologic, clinical, and microbiologic analysis of 3 clusters of cases from 2000 to 2003. Medicine (Baltimore) 2006 May;85(3):139-46. DOl PubMed

21. Curtis SJ, Tanna A, Russell HH, Efstratiou A, Paul J, Cubbon $M$, Sriskandan S. Invasive group A streptococcal infection in injecting drug users and non-drug users in a single UK city. J Infect 2007 May;54(5):422-6. DOl PubMed

22. Lamagni TL, Neal S, Keshishian C, Hope V, George R, Duckworth G, Vuopio-Varkila J, Efstratiou A. Epidemic of severe Streptococcus pyogenes infections in injecting drug users in the UK, 2003-2004. Clin Microbiol Infect 2008 Nov;14(11):1002-9. DOI PubMed

23. Kwiatkowska RM, Manley $P$, Sims B, Lamagni T, Ready D, Coelho J, Alsaffar L, Beck CR, Neely F; Outbreak Control Team. Outbreak of group A Streptococcus emm94.0 affecting people who inject drugs in southwest England, April 2017. Am J Infect Control 2018 Feb;46(2):238-40. DOI PubMed

24. Finkelstein M, McGeer A, Sachdeva H, Dohoo C, Stuart R, Kaplan E, Hayden D, Rea E, Gournis E. Outbreak of group A Streptococcus (GAS) in a shelter for homeless men, Toronto, Canada. Student poster presentation P48, Association of Medical Microbiology and Infectious Disease Canada (AMMI), Toronto ON), 2017. https://jammi.utpjournals.press/ doi/pdf/10.3138/jammi.2.suppl-1.1

25. Cady A, Plainvert C, Donnio PY, Loury P, Huguenet D, Briand A, Revest M, Kayal S, Bouvet A. Clonal spread of
Streptococcus pyogenes emm44 among homeless persons, Rennes, France. Emerg Infect Dis 2011 Feb;17(2):315-7. DOI PubMed

26. Bundle N, Bubba L, Coelho J, Kwiatkowska R, Cloke R, King S, Rajan-lyer J, Courtney-Pillinger M, Beck CR, Hope V, Lamagni T, Brown CS, Jermacane D, Glass R, Desai M, Gobin M, Balasegaram S, Anderson C. Ongoing outbreak of invasive and non-xinvasive disease due to group $A$ Streptococcus (GAS) type emm66 among homeless and people who inject drugs in England and Wales, January to December 2016. Euro Surveill 2017 Jan;22(3):30446. DOI PubMed

27. Mosites EM, Frick AR, Grounder P. Outbreak of a rare subtype of group A Streptococcus - Alaska, 2016-2017. State of Alaska Epidemiology Bulletin. 2017;19(2):110. http://epibulletins.dhss.alaska.gov/Document/ Display?Documentld=1938

28. Mosites E, Frick A, Gounder P, Castrodale L, Li Y, Rudolph K, Hurlburt D, Lecy KD, Zulz T, Adebanjo T, Onukwube J, Beall B, Van Beneden CA, Hennessy T, McLaughlin J, Bruce MG. Outbreak of invasive infections from subtype emm26.3 group A Streptococcus among homeless adults-Anchorage, Alaska, 2016-2017. Clin Infect Dis 2018 Mar;66(7):1068-74. DOI PubMed

29. Milne LM, Lamagni T, Efstratiou A, Foley C, Gilman J, Lilley M, Guha S, Head F, Han T. Streptococcus pyogenes cluster in a care home in England April to June 2010. Euro Surveill 2011 Nov;16(47):20021. DOl PubMed

30. McNutt LA, Casiano-Colon AE, Coles FB, Morse DL, Menegus M, Groth-Juncker A, Lansky J, Bell K, Schwartz $B$. Two outbreaks of primarily noninvasive group $A$ streptococcal disease in the same nursing home, New York, 1991. Infect Control Hosp Epidemiol 1992 Dec;13(12):74851. DOl PubMed 